\title{
On the Integration of Manufacturing Strategy: Deconstructing Hoshin Kanri
}

\section{Structured Abstract}

Purpose: To show that Hoshin Kanri has the potential to integrate the operations strategy literature into a coherent structure. Hoshin Kanri's planning process is typically described as a top-down cascading of goals, starting with the senior management's goals and moving to the lowest organizational level. We argue that this misrepresents a firm's actual cognitive processes in practice because: (i) it implies reasoning from the effects to the cause; and (ii) it assumes a direct causal relationship between what the customer wants and what is realizable by the system.

Design/methodology/approach: Conceptual; abductive, based on the literature.

Findings: The actual strategic thought process executed in an organization consists of three iterative processes: (i) a translation process that derives the desired customer attributes from customer/stakeholder data; (ii) a process of causal inference that predicts realizable customer attributes from a possible system design; and, (iii) an integrative process of strategic choices whereby (i) and (ii) are aligned. Each element relies on different cognitive processes (logical relation, causal relation and choice).

Research implications: By aligning the thought and planning processes, the competing concepts of manufacturing strategy are integrated into a coherent structure.

Practical implications: Different techniques have to be applied for each of the three elements. Since each element relies on different cognitive processes (logical relation, causal relation and choice), the use of unifying tools (e.g. in the form of matrices, as often presented in the literature) is inappropriate.

Originality/value: The first study to focus on the thought processes underpinning manufacturing strategy.

Keywords: Hoshin Kanri; Manufacturing Strategy; Operations Strategy; Strategy Deployment; Strategic Decisions; Causality; Trade-Offs.

Article Classification: Conceptual Paper 


\section{INTRODUCTION}

Hoshin Kanri is a multi-level, collective strategic implementation and planning methodology that has been viewed as a promising means of achieving both the horizontal and vertical coordination of operations strategy (Ishikawa, 1990; Akao, 1991). The first wave of implementations of Hoshin Kanri in the 1980s (e.g. at Toyota and Hewlett Packard) was followed by steady adoption by other global leaders (Ettlie, 1997; Lee \& Dale, 1998; Witcher \& Butterworth, 1999, 2000; Witcher, 2003; Babich, 2005; Witcher et al., 2008). According to Witcher (2014), virtually all vehicle and car companies use Hoshin Kanri, partly due to the success of companies such as Toyota and Nissan and the use of the approach by their suppliers (Witcher \& Butterworth 2001). Meanwhile, Hoshin Kanri has also been applied to other sectors, such as healthcare (e.g. Melum \& Collett, 1995). Firms adopting Hoshin Kanri believe it is essential for lean operations (e.g., Dennis, 2007) and can help coordinate the complexities of a modern, global organization (e.g. Chen \& Miller, 2010).

Strategy formulation initiates operations strategy, and is the primary responsibility of senior management. After identifying the strategic goals, senior management initiates a Hoshin Kanri cycle. The Hoshin Kanri cycle is a repeating, periodic (typically on an annual basis) PDCA (Plan-Do-Check-Act) cycle that is enhanced by Hoshin Kanri's unique components; it aims to determine operational actions consistent with the achievement of the strategic goals (Witcher \& Butterworth, 1997). The cycle starts with the Plan phase, which cascades senior management's goals down to the lowest organizational level as a set of annual hoshins. These annual hoshins communicate a company's strategic goals and, more importantly, the proposed means for achieving these goals. By simultaneously communicating the goals and the mechanisms for achieving them, Hoshin Kanri acts like a compass that guides a firm's efforts. Specifically, the means at one level become the targets or goals for the next lower level. Through this cascading process, senior management's goals are translated into operational targets. In the Do phase of PDCA, the Hoshin Kanri cycle ensures each level implements its plan through activities focused on realizing the goals identified in the Plan phase.

Next, in the Check phase of PDCA, the Hoshin Kanri cycle consists of a set of planned periodic reviews that measure each level's progress versus its hoshin targets. The Check phase provides management with the opportunity to identify any shortcomings in the plan. Here, the manager at each level measures actual goal accomplishment against target accomplishment and 
engages in micro PDCA cycles to improve performance if the level has not reached the target performance. The level may engage in multiple PDCA cycles to resolve outstanding problems. As the year progresses, the higher level units use the department reports to measure their own progress versus their targets. They too can engage in mid-year PDCA activities to improve their performance versus their targets. As the year progresses further, the firm starts the Act phase of the Hoshin Kanri cycle, in which the firm will decide what worked effectively and what must be changed. The firm completes this Hoshin Kanri cycle in the Act phase by analyzing the data to determine what revisions to make to the hoshin for the next year (e.g. Babich, 2005; Jackson, 2006). A new Hoshin Kanri cycle typically emerges and is subsequently initiated upon completion of the Act stage of the previous cycle.

In one sense, all firms practice some form of Hoshin Kanri, since all firms communicate goals and seek to implement mechanisms/processes to achieve these goals, regardless of their level of formality. But many companies struggle with building effective links (da Silveira et al., 2017). Given the proliferation of elements of the Hoshin Kanri cycle, its thorough examination can inform firm-level strategy implementation. However, although Hoshin Kanri is well-regarded as an effective strategy implementation tool, we argue that its underlying cognitive processes and, consequently, the respective processes of firms that use less structured deployment processes, are not fully understood. We expect that clearly stating and explaining these thought processes will improve our ability to implement Hoshin Kanri.

The current Hoshin Kanri literature considers the planning process to be 'linear' - i.e., senior management cascades its goals down to the lowest organization level. But this implies that managers reason from the effects (the desired output of the system) to the cause (a set of input variables for system manipulation), which, to the best of our knowledge, is not possible. The relationship between quality and zero defects, for example, presents a logical relationship that can be cascaded down; but the effect of changes in machine parameters on defect rates is a causal relationship. It is not possible to derive the machine parameters from the desired defect rate but rather our cognitive process proceeds iteratively, e.g. by estimating what would be the defect rate for a certain machine parameter. This confusion between a logical and causal relationship may also be at the heart of another prevailing short-coming in the operations strategy literature - that "the set of cause-and-effect factors which determine the linkage between strategy and production operations" (Skinner, 1969; p. 139) is elusive. We argue that these cause-and- 
effect factors do not in fact exist, as we cannot speak about causal processes when we refer to a (strategic) choice. Cooperate strategy seeks to determine what are the desired customer attributes. Manufacturing strategy is a pattern of structural and infrastructural decisions that determine the capability of a manufacturing system and specify how it will operate to realize a given set of attributes. While these realizable attributes should be consistent with the desired attributes (Platts et al., 1998), the system may not be able to realize all desired attributes since production operations are subject to causal constraints that determine what are the realizable attributes. To the best of our knowledge, there is no causal relationship between desired and realizable attributes, but this is a strategic choice. This may explain why management research and practice still struggles to establish the causal links that determine organizational performance (de Waal \& Goedegebuure, 2017).

Hence, the main contribution of this paper is to revise the description of Hoshin Kanri, resolving both misconceptions - (i) the confounding of logical and causal relationships; and (ii) the confounding of causal relationship and choice. It is expected that clarifying this distinction will facilitate Hoshin Kanri's implementation and help to unlock the full potential of the approach as an integrative tool for operations strategy. By deconstructing Hoshin Kanri's planning process, we reveal its structure and attempt to integrate the hoshin planning and operations strategy literature.

The remainder of this paper is structured as follows. Section 2 introduces Hoshin Kanri before Section 3 outlines our methodology. Section 4 then deconstructs the Hoshin Kanri planning process. The relationship between Hoshin Kanri and operations strategy is discussed in Section 5. Finally, the paper concludes in Section 6.

\section{RELATED LITERATURE}

This section discusses the Hoshin Kanri literature to illustrate the deployment process and provide the ground for our argumentation. It is not a comprehensive literature review, but rather literature is used to support our task. For a comprehensive literature review the reader is referred to e.g. Jolayemi (2008).

Hoshin Kanri is a multi-level strategic planning methodology based on collective planning and implementation principles. Its objective is to link senior management's goals to operational targets that allow for the realization of these goals. Hoshin Kanri co-evolved with Total Quality 
Management (TQM) in Japanese firms, starting in the 1950s, as executives sought to enhance their quality improvement efforts (Witcher \& Butterworth, 1999; Babich, 2005; Nicholas, 2014). To improve the definition of their quality goals, Japanese firms first integrated the Deming Cycle (i.e. Plan-Do-Check-Act: PDCA) into their enterprise-wide planning systems (Ishikawa, 1990). They then adopted Drucker's (1954) Management by Objectives (MbO) to instill goal clarity into their quality systems. For example, the Deming Prize incorporated many Hoshin Kanri concepts into its checklist in 1958 (Wood \& Munshi, 1991; Jackson, 2006) and accelerated its diffusion in Japan as firms sought to imitate the prize winners (Babich, 2005). However, while the origins of Hoshin Kanri in Japan owe much to MbO, in Western organizations MbO has often been used to simply cascade down management objectives and to control the performance of subordinates, rather than to manage the objectives themselves. Similarly, the balanced scorecard - another related policy deployment technique introduced by Kaplan \& Norton (1992) - is strong in defining what should be done, but it has little to say about how this should be done (Witcher 2014). In contrast, Hoshin Kanri emphasizes unique techniques such as 'catchball', which refers to feedback cycles between the different levels of an organization on what should be achieved, what can be achieved and, most importantly, how it can be achieved (da Silveira $e t$ al., 2018).

A common portrayal of the overall Hoshin Kanri process is shown below in Figure 1 - in this study, we focus on Hoshin Kanri's planning process, which will be discussed next.

\section{[Take in Figure 1]}

\subsection{Hoshin Kanri: The Planning Process}

The literature models Hoshin Kanri planning as a hierarchical process that links the different parts of the organization through the process of issuing hoshins, which then cascade vertically through the organization. The Hoshin Kanri process uses teams to coordinate the plans as they are developed throughout the organization. For example, Jackson (2006) divides the organization into hoshin teams, tactical teams, operational teams and action teams. To create high quality decisions and avoid decision bias these teams should be heterogeneous (Cristofaro, 2017) with appropriate conflict resolving mechanism in place (Parayitam \& Papenhausen, 2018).

Since the cascading process allows each team to work independently, a question of governance arises - how is it best to co-ordinate targets (and thus activities) across these 
disparate teams? The literature has proposed that consensus and thus alignment across levels is achieved through a so-called catchball process (e.g. Jackson, 2006). The term catchball refers to an iterative process in which information and ideas are "thrown" and "caught" vertically and horizontally throughout the organization. Catchball consists of discussion and feedback about goals and the means to achieve these goals. During this consensus building process, the goals and resource allocations can be affected (Cowley \& Domb, 1997; Tennant \& Roberts, 2001). It is meant to close the "knowing-doing" gap described by Pfeffer \& Sutton (2000) and, when properly aligned, may lead to "double-loop" learning (Argyris, 1982). The catchball process actually begins with a carefully written hoshin; it represents the operationalization of the strategy. The hoshin is a clear statement of the goals and the means to achieve these goals, and it serves as a constraint on the levels below. The cascading down of objectives is done by passing on the hoshin.

As illustrated in Figure 2, the catchball process includes the initial cascade down of the objectives. This is followed by a roll-up of the plans to consolidate local plans and check for the capability and likelihood of their execution (Bechtell, 1996; Jackson, 2006). As each vertical level receives its hoshin, it translates it for the level below by taking the means given to them and making these means the goal for the next level.

\section{[Take in Figure 2]}

There are three important components of the hoshin (Shiba \& Walden, 2001). One is the goal/target, the second is the means by which this goal is to be accomplished, and the third is the metric by which the accomplishment is to be measured. An individual hoshin may not be unique, but the formalization of these three core elements together makes it unique.

There exists broad evidence on the beneficial effect of strategic alignment. Hoshin Kanri achieves strategic alignment by linking the means and goals of each level of the company through the deployment process described above. However, while Hoshin Kanri's planning process appears to be well understood in the literature, we argue that it overlooks an important distinction in the type of relationship between the goals and means (at each level and in-between levels). This relationship may be either a logical relationship, such as between being cheap and costing less than $\$ 100$, or a causal relationship, such as between changing a machine parameter and obtaining a certain throughput rate. Moreover, means at a higher level, which become goals 
for a lower level, may not be realizable - hence, choices have to be made. We therefore look beyond the documented components of Hoshin Kanri's planning process. Our vehicle is a deconstruction of its thinking process based on abductive reasoning.

\section{METHODOLOGY}

Our study develops an argument based on reasoning. To the best of our knowledge, there is no methodological account of scientific reasoning, whether it be deductive, inductive or abductive. We closely follow the definition in Peirce (1998), so our reasoning is mainly abductive. Abductive reasoning draws an inference to a possible explanation. It is followed by deductive reasoning to determine testable consequences and inductive reasoning to empirically test these consequences; the latter is considered to be outside the scope of this study. Abductive reasoning does not rule out alternative explanations, rather the normative ideal is the selection of the 'best explanation'. The criterion for assessing our reasoning is therefore its coherence within a system of statements.

The best way of achieving this coherence is via the use of formal language, but management theory is often only expressible in natural language. Mantere \& Ketokivi (2013) go so far as to claim that no theory about organizations is logically coherent in a normative sense. Management theory is therefore often based on implicit reasoning, which simply goes from the likeness of one case to another without explaining in what sense the likeness exists. In contrast, explicit reasoning occurs when the mind recognizes the relationship between two experiences and explains the nature of the relationship (Aram \& Salipante, 2003). Since our argument is based on implicit reasoning, we must illuminate the underlying logic instead of relying on formal language (Mantere \& Ketokivi, 2013).

Any evaluation of our argument then centers on the transparency of the deductive chain of evidence - the creditability and plausibility of the theoretical 'story' presented. It is this narrative paradigm and its associated narrative rationality (Fisher, 1987) that builds the methodological background to our study.

\section{THEORETICAL DEVELOPMENT}

\subsection{The Plan Phase of Hoshin Kanri: Deconstruction of its Thinking Process}

Consider the following statements: 
Statement 1: The customer/management wants a high quality product.

Statement 2: The customer/management wants a product with a certain value of a measureable quality characteristic A.

Statement 3: The system produces a product with a certain value of a measureable quality characteristic A.

Statement 4: The system variable $\mathrm{X}$ should be set to a certain target value so the desired value of measureable quality characteristic A can be realized.

The objective of Hoshin Kanri's planning process is the determination of Statement 4 from Statement 1 . The literature argues that this is achieved by 'cascading down', i.e. from Statement $1 \rightarrow$ Statement $2 \rightarrow$ Statement $3 \rightarrow$ Statement 4 . Here, it is argued that this necessarily implies reasoning from effects (Statement 3) to the cause (Statement 4). While the link between Statement 1 and Statement 2 is a logical and thus symmetrical relationship (i.e. 'a high quality product is a product with a certain value of a measureable quality characteristic $A$ ' and 'a product with a certain value of a measureable quality characteristic A is of high quality' are equivalent statements), the link between Statement 3 and Statement 4 is a causal relationship and thus asymmetrical (i.e. 'the process variable $\mathrm{X}$ at a certain target value causes a certain value of measureable quality characteristic A' cannot be transposed into the statement 'a certain value of measureable quality characteristic $A$ causes the process variable $X$ to be at a certain value'). It is, to the best of our knowledge, impossible to reason from Statement 3 (the goal) to Statement 4 (the means). Rather, an iterative process of reasoning from Statement 4 to Statement 3, evaluating different settings for Statement 4 , is applied. Our claim is supported by the vast literature on the design of experiments - which uses experiments (i.e. different settings of the possible cause) to determine the effect. This literature would be meaningless if reasoning from the effect to the cause were possible. Therefore, we argue for two very different deployment processes before the outcomes of the processes are aligned through a set of strategic choices, i.e. Statement $1 \rightarrow$ Statement 2 - choice - Statement $3 \leftarrow$ Statement 4 .

From the above, it follows that the Hoshin Kanri planning process that is actually executed must consist of two deployment processes. The first is a process of translation and clarification (Statement $1 \rightarrow$ Statement 2). The second is a process of causal inference, which uses causal relationships between 'real' variables to allow for system manipulation (Statement $4 \rightarrow$ Statement 3). Both are aligned by strategic choices (i.e. the decision of the organization 
concerning which of the attributes from the set of attributes desired by the customer to realize) at a so-called Clash with Reality frontier.

The Clash with Reality frontier highlights the second misconception of Hoshin Kanri's planning process as being a linear process. In practice, there is an apparent disconnect between what the customer/manager wants and what is physically possible. There is no restriction on the former but the latter is constrained by current operational capabilities and available resources during the Do phase. This disconnect cannot be bridged by any relationship (whether causal or logical), but rather it is a question of strategic choice. In our example above, quality characteristic A may not be realizable by the shop or only realizable by investing heavily in new equipment - so a choice has to be made regarding what degree of quality characteristic A can (and should) be realized. This choice is only bound by available resources; there is no relationship between Statement 2 and Statement 3. While this Clash with Reality is implicitly recognized in the practitioner literature about Hoshin Kanri, scholarly treatment of this assumption requires explicit refinement. For example, Rochetti (2016) states that after top management has approved the plan, it needs to be validated by middle management, which is responsible for asking: "What could get in the way of making this a reality?" (Rochetti, 2016; p. 27).

\subsection{A Framework of Hoshin Kanri's Planning Process}

Figure 3 illustrates our understanding of the different parts involved in Hoshin Kanri's planning process. All are required to determine appropriate values $\left[\hat{x}_{1}, \hat{x}_{2}, \ldots \hat{x}_{k}\right]$ for a set of $D o$ variables, i.e. variables on which to intervene after the Plan phase and during the Do phase. In what now follows, we use upper case letters to denote a set of variables and lower case letters for specific variables.

\section{[Take in Figure 3]}

The different parts of the process can be summarized as follows:

- Translation: This process converts texts into a set of desired customer attributes (such as quality characteristics, speed of delivery, price, etc.) $-\left[a_{1}^{*}, a_{2}^{*}, \ldots a_{n}^{*}\right]-$ which are measureable, and thus, specific. The objective is to distill what is meant by the customer/management interpreting the texts. Texts refer to printed matter, recorded speech, visual communication, works of art, artefacts, etc. These texts are produced by the customer(s), management or 
other stake/shareholders to which the process shall be aligned. The main techniques for interpreting the texts come from social sciences, e.g. in the form of content analysis.

- Clash with Reality: This is the frontier between the translational and causal deployment processes. Here, the set of desired customer attributes and the set of realizable customer attributes $-\left[a_{1}, a_{2}, \ldots a_{n}\right]$ - have to be aligned. This is achieved through strategic choices (Scott, 2003). It is here, and only here, that the 'cause-and-effect' factors that link strategy and operations (Skinner, 1969) are found. But it is apparent that it is not a causal link but rather a strategic decision or choice bounded by the organization's internal and external resources.

- Product/Service Design: All realizable customer attributes are determined by the system design, i.e. the variables and the variable-linking structure. But a part of these variables is mediated - and thus can be influenced - by the product/service design. For example, the same function of a product may be realized by a design that requires a large set of complex system operations or a small set of simple system operations. The main techniques are based on causal inference.

- System Design: This process determines a set of Do variables $\left[\hat{x}_{1}, \hat{x}_{2}, \ldots \hat{x}_{k}\right]$ through which a specific set of system variables $\left[y_{1}, y_{2}, \ldots y_{m}\right]$ can be realized. The set of system variables describes the product/service system. It is comprised of a set of Do variables and a set of state variables $\left[z_{1}, z_{2}, \ldots z_{j}\right]$. State variables, e.g. throughput times, lead times and quality standards, are all system variables that cannot be realized through direct intervention. Rather, they are the output of the system. These variables play the most important role during the Check phase as Do variables are expected to be at a certain target value. The main techniques for system design are based on causal inference.

Our description above suggests that the Hoshin Kanri deployment process is not a linear process of cascading down. Rather, the translation of a set of desired customer attributes from texts, and the inference of realizable customer attributes from a set of $D o$ variables, has to be executed simultaneously with the alignment process that occurs at the Clash with Reality frontier (through strategic choices). In other words, it is not possible to just change the value of a realizable attribute - this change has to be based on a Do variable and an inferential process to predict the effect of this change on the realizable attribute. In the absence of these steps being 
synchronized, a firm is left to search "in the dark" for alignment, relying on poorly understood micro-level social activities (e.g. Jarzabkowski \& Balogun, 2009), as it lurches towards some form of 'fit' (cf. Siggelkow, 2002).

\section{THE INTEGRATION OF OPERATIONS STRATEGY}

Operations strategy is an important component of a firm's overall strategy; it is critical to its operational success, and thus has been a core focus of management research for many decades (e.g. Skinner, 1969, 1996; Leong et al., 1990; Roth \& Miller, 1992; Miller \& Roth, 1994; Hayes \& Pisano, 1996;). Yet the literature on operations strategy appears to be fragmented. For example, Skinner (1969), and later Voss (1995, 2005), identified three main aspects of operations strategy: (i) competing through manufacturing, which means that manufacturing provides the firm with a particular competitive advantage, which in turn determines the particular strategic demands on the manufacturing function (or similarly on a service process); (ii) strategic choices, such as determining which demands should be fulfilled; and (iii) the identification of best practices, which are then used to design the manufacturing function to fulfill the demands chosen in part (ii). The authors did not however fully explain why these three aspects should emerge, which hinders a full understanding of their relationship. Hoshin Kanri is a useful framework for explaining the emergence of these three aspects of operations strategy; specifically, Hoshin Kanri's deconstruction suggests that these three aspects emerge because each relates to a different way of thinking (interpretation, choice, and causal reasoning), which explains why they are so 'remarkably robust' (Voss, 2005; p. 1223):

(i) Competing through manufacturing: Competing through manufacturing requires a firm to identify the order-qualifying and order-winning criteria (i.e. the firm's competitive priorities). The firm uses these criteria to secure an initial market position and to sustain this competitive position in the market over time (Hill, 1993). In other words, this aspect of operations strategy is concerned with identifying what the customer wants and tracking changes in customer preferences over time. This is a process of interpretation or translationnot a process of choice or causal reasoning. To be successful at this, firms must first unravel the meaning of the qualitative data or descriptive texts and images that they receive from their current and potential customers. This requires firms to have the ability to translate this 
often non-quantitative and possibly conflicting data into a set of desired customer attributes (i.e. a set of measureable variables).

(ii) Strategic choices - Alignment: Strategic choice is essentially about aligning desired and realizable customer attributes. It is literally a question of choice - since there is not a logical or causal relationship between what the customer wants and what the firm can provide. This recognition of the nature of strategic choices is the essential subject of the trade-off and cumulative models of operations strategy that have been extensively examined in the operations literature (e.g. Nobel, 1997; Schmenner \& Swink, 2004; Rosenzweig \& Easton, 2010; Sarmiento et al., 2013, 2016). For example, the trade-off model claims that the decision of a firm to focus on one set of customer attributes means that the firm must necessarily choose not to provide some other set of customer attributes.

(iii) Best practices - Causal inference: The concept that firms can adopt best manufacturing practices is contingent upon the ability of firms to identify and then adapt these practices to their existing operating system (e.g. Sousa \& Voss, 2008). Specifically, this means that firms must be able to search for and identify superior performance results and then, once observed, firms must be able to analyze these results in order to derive the underlying operations practices. Restated, firms have to identify the underlying cause-and-effect relationships. This reasoning always has to start with possible causes that may explain superior performance results, many of which rely upon micro-foundations that are unobservable or ambiguous in nature. To open this "black box", firms need to evaluate through experimentation. To be successful, the firm needs to identify the cause-and-effect relationships underlying best practices and determine how to integrate them into their existing operations in order to achieve a sustainable competitive advantage. As Abrahamson \& Fairchild (1999) demonstrated, this is not a simple task and it is made more complicated by the large amount of rhetoric in the discourse about management techniques. Approaches to doing this have been the subject of the organizational learning literature that is interested in understanding how organizations learn about best practices, interpret these practices and help to institutionalize them. This process requires both feed-back learning and feed-forward learning to be successful. In this process, firms identify their key processes and examine how to integrate the "new" best practices into their key processes, and then how to diffuse these best practices throughout the firm. Best practices can be diffused (and thus replicated) since 
they are based on at least partially invariant cause-and-effect relationships. Within the Hoshin Kanri planning process, best practices affect the relationship between Do variables and realizable customer attributes, yielding actionable tactical and operational plans through multiple feedback loops.

Hoshin Kanri provides an organizing framework to integrate the operations strategy literature. In doing so, it extends the commonly applied distinction between the content and process of operations strategy (Leong et al., 1991; Hayes et al., 2008; Slack \& Lewis, 2008). Content and process variables are a subdivision within each of the three aspects of the operation strategy literature - competing through manufacturing, strategic choices and best practices. But the relationships between content and process variables are different for each, since a different thinking process needs to be applied. Both - content and process variables - are represented in Figure 3. For example, the variable (A, P, X, Y and Z) are the content variables. Meanwhile, the process variables are represented by the arrows - these are the methods that Hoshin Kanri uses to iterate between its current state $(\mathrm{Z})$ to both its system design $(\mathrm{Y})$ and its product design $(\mathrm{P})$ to identify the necessary system inputs $(\mathrm{X})$ to move the state in the correct direction to result in the realizable customer attributes $(\mathrm{A})$.

Hoshin Kanri's organizing framework clarifies the inter-relationships between the different parts of operations strategy presented in the literature. For example, Voss (1995) sees the three aspects of operations strategy as creating a continuous cycle, as depicted in Figure 4a, in which a firm that is "competing through manufacturing" makes "strategic choices" that lead to new "best practices", which then affects its ability to compete. The interpretation of the Hoshin Kanri framework provided above suggests that the cycle in Figure 4a does not fully represent the process of planning in manufacturing strategy. This framework suggests that the alternative planning process illustrated in Figure $4 \mathrm{~b}$ is more representative. Competing through manufacturing and best practices are not directly connected but have to be aligned through strategic choices. Meanwhile, although management chooses the best practice to be applied as part of strategic choices, it is the best practice that causes this choice. The best practice determines the realizable attributes and thus constrains the strategic choice. If the choice is to realize 100 pieces per hour (desired attribute) then this does not determine the best practice to realize 100 pieces per hour (and whether this is possible at all). Rather, the potential effect of different best practices has to be taken into account when making this choice. This potential 
effect cannot be determined starting from the performance results of a best practice due to the nature of the underlying invariant cause-and-effect relationships. Thus, realizable attributes, determined by best practices, and desired attributes, determined by competing through manufacturing, have to be aligned in an iterative process of strategic choice. This iterative process is illustrated by an additional arrow in Figure $4 \mathrm{~b}$, which relates to feedback on the possible effect of different best practices potentially derived from experiments.

[Take in Figure 4]

\section{CONCLUSIONS}

Translating corporate strategy into operations strategy has been a key focus of Operations Management for many decades. Yet the field still awaits a comprehensive framework that integrates the literature concerned with implementing operations strategy. We argue that Hoshin Kanri holds the key to this integration; however, there is a major disconnect between how Hoshin Kanri's planning process is executed in practice and how it is modeled in the literature. The literature argues for a 'linear' planning process that cascades senior management's goals down to the lowest organization level. We argue that this misrepresents a firm's actual cognitive processes in practice because: (i) it implies reasoning from the effects to the cause; and (ii) it assumes a direct causal relationship between what the customer wants and what is realizable by the firm's operating system.

This paper has deconstructed Hoshin Kanri's planning process to explain how it can provide an integrating framework for operations strategy implementation. Our analysis demonstrates that there are two distinct deployment processes that have to be executed simultaneously to achieve alignment through a set of strategic choices. This divides Hoshin Kanri's planning process into three distinct parts: a translation process, a process of alignment (or choices), and a process of causal inference to predict the effect of system manipulation, as illustrated in Figure 3. The understanding of the Hoshin Kanri process based on this deconstruction helps to integrate the operations strategy literature in two ways. First, it provides an explanation of why literature on operation strategy can recurrently be subdivided into three different streams - competing though manufacturing, strategic choices and best practices. Our analysis argues that each separated stream of research emerges because each relates to a different way of thinking (interpretation, choice, and causal reasoning). Second, it provides a first step in integrating the three streams of 
literature into a holistic whole by providing a framework that relates the different thought processes to each other.

\subsection{Managerial Implications}

Our study has revealed that comprehensive strategic planning - such as in the form of Hoshin Kanri - entails several differing thought processes (logical relation, causal relation and choice). Different techniques have to be applied for each of these thought processes. The use of unifying tools (e.g. in the form of matrices, as often presented in the literature) is inappropriate if, for example, causal and logical relations are used in the same matrix. Rather, separate tools need to be applied for interpreting logical relationships (e.g. from content analysis), making choices (e.g. from game theory) and discovering the causal relationships that may result in best practices (e.g. by use of directed acyclic graphs).

\subsection{Limitations and Future Research}

This study is based on abductive reasoning that draws an inference from initial observation to a possible explanation. It should be followed by deductive reasoning to determine testable consequences and inductive reasoning to empirically test these consequences. Both are considered outside the scope of this study, which is a major limitation. While the limitation is justified by the need to keep the study focused and provide room for our argumentation, future empirical research is required. Meanwhile, and as highlighted above, separate tools initially need to be developed for interpreting logical relationships, making choices and discovering the causal relationships that may result in best practices. But later, these tools need to be integrated. The goal of this research stream is promising, but our paper represents only the first step towards a comprehensive, theory-driven framework. Finally, future research should also build on our contribution at the Plan phase by exploring how to realize the targets set in the Do phase, how to ensure the targets are achieved in the Check phase, and how to standardize success in the Act phase. This will unlock the full integrative potential of Hoshin Kanri as a strategic implementation and planning methodology and enhance its contribution to Operations Management. 


\section{References}

Abrahamson, E., and G. Fairchild. 1999. Management Fashion: Lifecycles, Triggers, and Collective Learning Processes. Administrative Science Quarterly 44: 708-740.

Akao, Y. 1991. Hoshin Kanri: Policy deployment for successful TQM. Cambridge MA: Productivity Press.

Aram, J.D., and Salipante, P.F. 2003. Bridging Scholarship in Management: Epistemological Reflections. British Journal of Management 14: 189-205.

Argyris, C. 1982. Reasoning, learning, and action: Individual and organizational. Jossey-Bass: San Francisco: CA.

Babich, P. 2005. Hoshin Handbook. Poway CA: Total Quality Engineering, Inc.

Bechtell, M.L. 1996. Navigating Organizational Waters with Hoshin Planning. National Productivity Review (Spring) 23-42.

Chen, M.J., and Miller, D. 2010. The relational perspective as a business mindset: Managerial implications for East and West. Academy of Management Perspectives (25): 6-18.

Cowley, M., and Domb, E. 1997. Beyond strategic vision: Effective corporate action with hoshin planning. Boston MA: Butterworth-Heinemann.

Cristofaro, M. 2017. Reducing biases of decision-making processes in complex organizations. Management Research Review 40(3): 270-291.

da Silveira, W.G., de Lima, E.P., da Costa, S.E.G., and Deschamps, F. 2017. Guidelines for Hoshin Kanri implementation: development and discussion, Production Planning \& Control 28(10): 843-859.

da Silveira, W.G., de Lima, E.P., Deschamps, F., and da Costa, S.E.G. 2018. Identification of guidelines for Hoshin Kanri initiatives. International Journal of Productivity and Performance Management 67(1): 85-110.

Dennis, P. 2007. Lean production simplified. $2^{\text {nd }}$ Edition Boca Raton, FL: CRC Press, Taylor \& Francis Group.

de Waal, A., Goedegebuure, R. 2017. Investigating the causal link between a management improvement technique and organizational performance: The case of the HPO framework. Management Research Review 40(4): 429-450.

Drucker, P. 1954.The Practice of Management. New York: Harper \& Brothers.

Ettlie, J. E. 1997. Quality, technology, and global manufacturing, Production \& Operations Management 6 (2): 150-166.

Fisher, W.R. 1987. Technical Logic, Rhetorical Logic, and Narrative Rationality. Argumentation 1:3-21.

Hayes, R.H., Pisano, G., Upton, D., and Wheelwright, S., 2008. Operations, strategy, and technology: pursuing the competitive edge. New York: John Wiley \& Sons.

Hayes, R. H., and Pisano, G.P. 1996. Manufacturing Strategy: At the Intersection of Two Paradigm Shifts, Production \& Operations Management 5(1): 25-41.

Hill, T. 1993. Manufacturing strategy. Macmillan, Basingstoke: Hampshire.

Ishikawa, K. 1990. Introduction to Quality Control. J. H. Loftus (trans.). Tokyo: 3A Corporation. 
Jackson, T.L.. 2006. Hoshin Kanri for the lean enterprise: Developing competitive capabilities and managing profit. New York, NY: CRC Press: Taylor \& Francis Group.

Jarzabkowski, P., and Balogun, J. 2009. The practice and process of delivering integration through strategic planning. Journal of Management Studies, 46 (8): 1255-1288.

Jolayemi, J.K. 2008. Hoshin kanri and hoshin process: A review and literature survey, Total Quality Management \& Business Excellence 19 (3): 295-320.

Kaplan R.S. and Norton D.P. 1992. The balanced scorecard - measures that drive performance. Harvard Business Review, January-February: 71-79.

Lee, R.G., and Dale, B.G. 1999. Policy deployment: a case study analysis.Production Planning \& Control 10 (5): 493-501.

Leong, G.K., Snyder, D.L., and Ward, P.T. 1990. Research in the process and content of manufacturing strategy. Omega 18 (2): 109-122.

Mantere, S., and Ketokivi, M. 2013. Reasoning in Organization Science. Academy of Management Review 3: 70-89.

Melum M.A. and Collett C. 1995. Breakthrough Leadership: Achieving organisational alignment through hoshin planning, Chicago IL: American Hospital Publishing.

Miller, J.G., and Roth, A.V. 1994. A taxonomy of manufacturing strategies. Management Science 40(3): 285-304.

Nicholas, J. 2014. Hoshin kanri and critical success factors in quality management and lean production, Total Quality Management \& Business Excellence 27 (3-4): 250-264.

Noble, M.A. 1997. Manufacturing competitive priorities and productivity: an empirical study. International Journal of Operations \& Production Management 17 (1): 85-99.

Parayitam, S., and Papenhausen, C. 2018. Strategic decision-making: The effects of cooperative conflict management, agreement-seeking behavior and competence-based trust on decision outcomes. Management Research Review 41(1): 2-28,

Peirce, C.S. 1998. Harvard Lectures on Pragmatism in The Essential Peirce: Volume 2, Indiana University Press

Pfeffer, J., and Sutton, R.I. 2000. The knowing-doing gap: How smart companies turn knowledge into action. Harvard Business School Press: Cambridge, MA.

Platts, K., Mills, J.F., Bourne, M.C., Neely, A., Richards, A. H., and Gregory, M. 1998. Testing manufacturing strategy formulation processes. International Journal of Production Economics 56-57: 517-523.

Rochetti, K., 2016. All Together Now: A method for better strategy deployment, aligning staff priorities with organizational goals, Quality Progress (April):, 20-28.

Rosenzweig, E. D., and Easton, G. S. 2010. Tradeoffs in Manufacturing? A Meta-analysis and Critique of the Literature. Production and Operations Management 19(2): 127-141.

Roth, A.V., and Miller, J.G. 1992. Success factors in manufacturing. Business Horizons 35(4): 73-81.

Sarmiento, R., Thürer, M., and Whelan, G. 2016. Rethinking Skinner's Model: Strategic TradeOffs in Products and Services. Management Research Review 39(10): 1199-1213. 
Sarmiento, R., Shukla, V., and Izar-Landeta, J.M. 2013. Performance improvements seen through the lens of strategic trade-offs. International Journal of Production Research 51 (15): 4682-4694.

Schmenner, R.W., and Swink, M.L. 1998. On theory in operations management. Journal of Operations Management (17): 97-113.

Scott, W. R. 2003. Organizations: Rational, natural, and open systems. Prentice-Hall: New York, NY.

Shiba, S., and Walden, D. 2001. Four Practical Revolutions in Management: Systems for Creating Unique Organizational Capability. $2^{\text {nd }}$ Edition, Productivity Press.

Siggelkow, N.2002. Evolution toward fit. Administrative Science Quarterly 47(1): 125-59.

Skinner, W. 1969. Manufacturing - missing link in corporate strategy. Harvard Business Review (May):136-145.

Skinner, W. 1996. Manufacturing Strategy on the 'S' Curve. Production \& Operations Management, 5 (1): 3-14.

Slack, N., and Lewis, M. 2008. Operations strategy. $2^{\text {nd }}$ edition. Harlow: Prentice-Hall.

Sousa, R., and Voss, C.A. 2008. Contingency research in operations management practices. Journal of Operations Management (26): 697-713.

Tennant, C., Roberts, P. 2001. Hoshin Kanri: Implementing the Catchball Process. Long Range Planning (34): 287-308.

Voss, C.A. 2005. Paradigms of manufacturing strategy re-visited. International Journal of Operations \& Production Management 25 (12): 1223-1227.

Voss, C.A. 1995. Alternative paradigms for manufacturing strategy. International Journal of Operations \& Production Management 15 (4): 5-16.

Witcher, B.J. 2003. Policy management of strategy (hoshin kanri). Strategic Change (12):83-94.

Witcher B.J. 2014. Hoshin Kanri through the eyes of English Language Texts. Journal of Business Studies 53(3): 72-90

Witcher, B.J, Butterworth, R. 1997. Hoshin kanri: A preliminary overview, Total Quality Management 8 (2-3): 319-323

Witcher, B.J, Butterworth, R. 1999. Hoshin Kanri: How Xerox Manages. Long Range Planning 32 (3): 323-332.

Witcher, B.J, and Butterworth, R. 2000. Hoshin Kanri at Hewlett-Packard. Journal of General Management 25 (4): 70-85.

Witcher B.J. and Butterworth R. 2001. Hoshin kanri: policy management in Japanese-owned UK subsidiaries. Journal of Management Studies 38(5): 651-674.

Witcher, B.J., Chau, V.S., and Harding, P. 2008. Dynamic capabilities: top executive audits and hoshin kanri at Nissan South Africa. International Journal of Operations \& Production Management 28 (6): 540-561.

Wood, G.R., Munshi, K.F. 1991. Hoshin Kanri: a systematic approach to breakthrough improvement. Total Quality Management 2 (3): 213-226. 


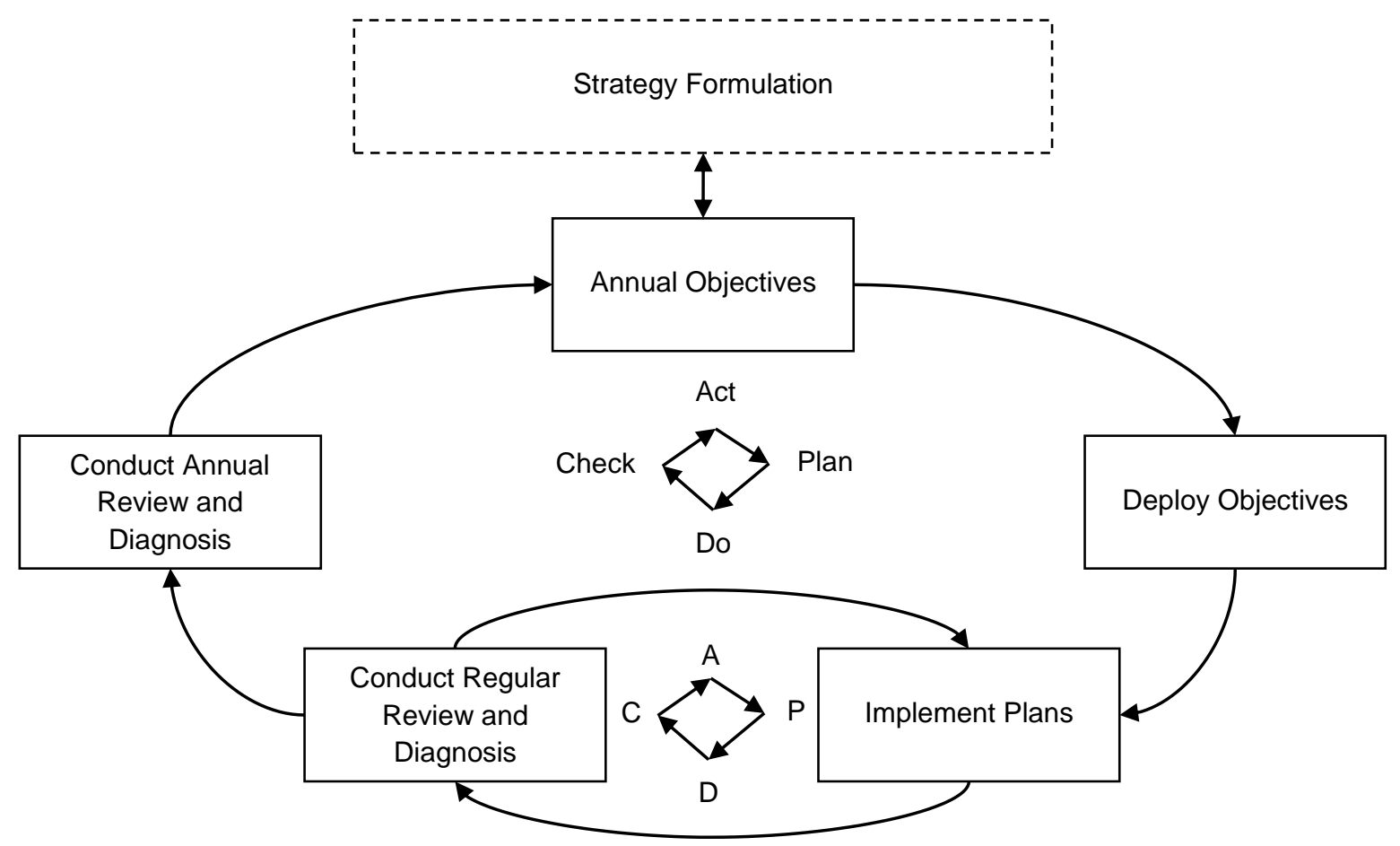

Figure 1: The Hoshin Kanri Cycle

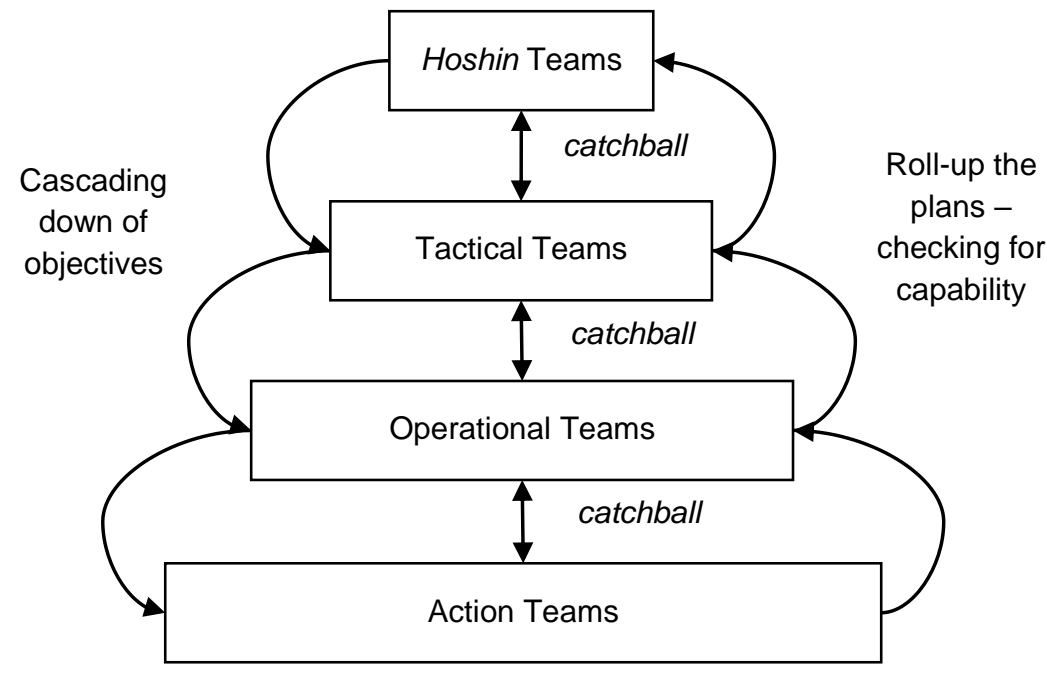

Figure 2: The Hoshin Planning (Deployment) Process, as Presented in the Literature (e.g. Bechtell, 1996; Jackson, 2006) 
Market Research

Input to the Planning Process

[Texts produced by management/customer]

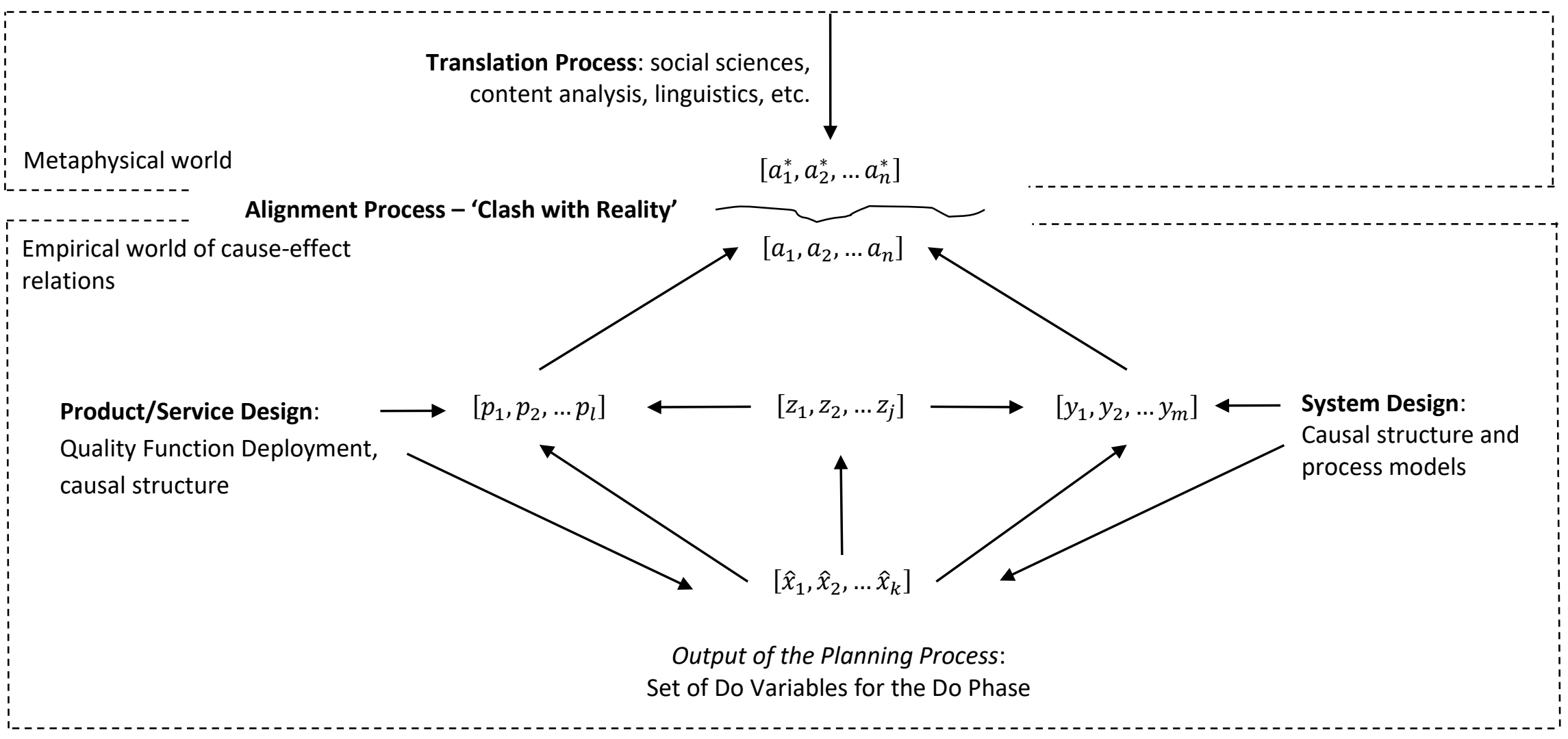

$\left[a_{1}^{*}, a_{2}^{*}, \ldots a_{n}^{*}\right] \quad$ Desired Customer/Stakeholder Attributes (Product Features, Delivery, Quality, Price)

$\left[a_{1}, a_{2}, \ldots a_{n}\right]$ Realizable Customer/Stakeholder Attributes (Product Features, Delivery, Quality, Price)

$\left[p_{1}, p_{2}, \ldots p_{l}\right] \quad$ Product Attributes (Product Features, Quality, Cost)

$\left[y_{1}, y_{2}, \ldots y_{m}\right]$ System Attributes (Delivery, Quality, Cost)

$\left[z_{1}, z_{2}, \ldots z_{j}\right] \quad$ System States (Delivery, Quality) - Check Variables

$\left[\hat{x}_{1}, \hat{x}_{2}, \ldots \hat{x}_{k}\right] \quad$ System Input Variables (Cost) - Do Variables

$$
\begin{aligned}
& {\left[a_{1}, a_{2}, \ldots a_{n}\right]=\left[p_{1}, p_{2}, \ldots p_{l}\right] \cap\left[y, y_{2}, \ldots y_{m}\right]} \\
& {\left[y_{1}, y_{2}, \ldots y_{m}\right]=\left[z_{1}, z_{2}, \ldots z_{j}\right] \cap\left[\hat{x}_{1}, \hat{x}_{2}, \ldots \hat{x}_{m}\right]}
\end{aligned}
$$

Figure 3: Analysis of Hoshin Kanri's Planning Process 


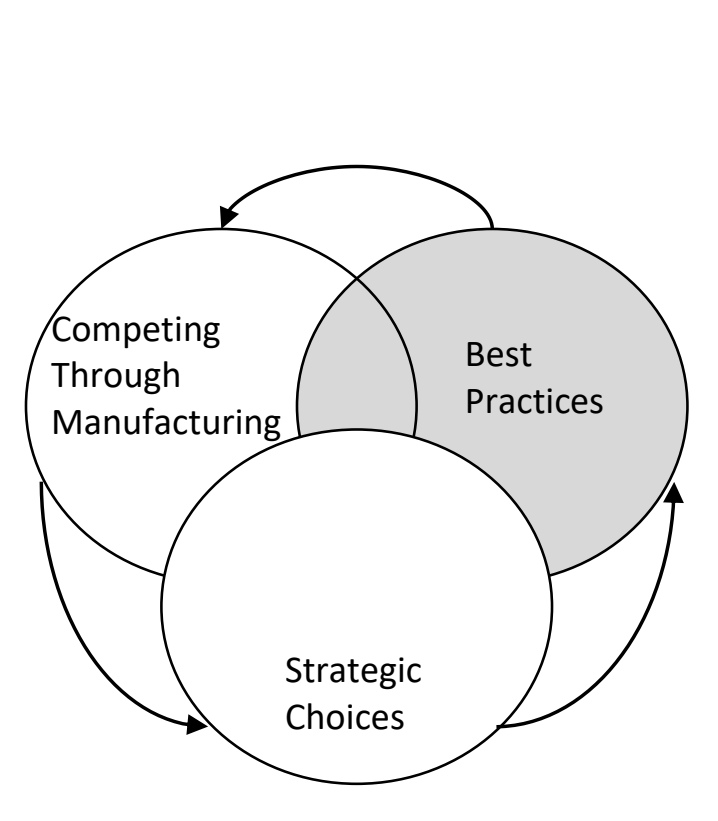

(a)
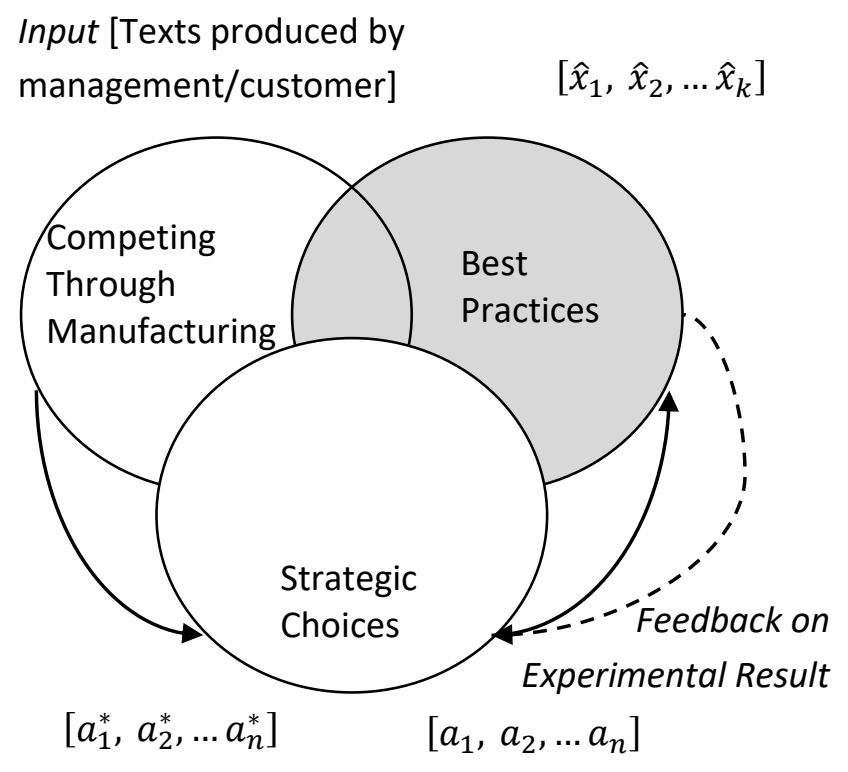

(b)

Figure 4: The Interplay between Competing Through Manufacturing, Best Practices and Strategic Choices: (a) From Voss (1995); (b) Proposed Planning Process 